\title{
вмJ Global Health Combating the COVID-19 pandemic in a resource-constrained setting: insights from initial response in India
}

\author{
GRID COVID-19 Study Group
}

To cite: GRID COVID-19 Study Group. Combating the COVID-19 pandemic in a resource-constrained setting: insights from initial response in India. BMJ Global Health 2020;5:e003416. doi:10.1136/ bmjgh-2020-003416

Handling editor Seye Abimbola

- Additional material is published online only. To view, please visit the journal online (http://dx.doi.org/10.1136/ bmjgh-2020-003416).

Received 10 July 2020 Revised 9 September 2020 Accepted 6 October 2020
Check for updates

(C) Author(s) (or their employer(s)) 2020. Re-use permitted under CC BY-NC. No commercial re-use. See rights and permissions. Published by BMJ.

Correspondence to GRID COVID-19 Study Group; archismn@gmail.com

\section{ABSTRACT}

The low-and-middle-income country (LMIC) context is volatile, uncertain and resource-constrained. India, an LMIC, has put up a complex response to the COVID-19 pandemic. Using an analytic approach, we have described India's response to combat the pandemic during the initial months (from 17 January to 20 April 2020). India issued travel advisories and implemented graded international border controls between January and March 2020. By early March, cases started to surge. States scaled up movement restrictions. On 25 March, India went into a nationwide lockdown to ramp up preparedness. The lockdown uncovered contextual vulnerabilities and stimulated countermeasures. India leveraged existing legal frameworks, institutional mechanisms and administrative provisions to respond to the pandemic. Nevertheless, the cross-sectoral impact of the initial combat was intense and is potentially long-lasting. The country could have further benefited from evidence-based policy and planning attuned to local needs and vulnerabilities. Experience from India offers insights to nations, especially LMICs, on the need to have contextualised pandemic response plans.

\section{INTRODUCTION}

In the absence of a specific treatment or vaccine for a global crisis like the COVID-19 pandemic, combative interventions are time-sensitive and resource-intensive. ${ }^{12}$ About $85 \%$ of the world's population (6.4 of 7.6 billion, 2018) reside in low-and-middle-income countries (LMICs). ${ }^{3}$ Methods such as social distancing, personal protection, aggressive contact tracing and isolation, and mass movement restriction seem untenable in LMIC contexts given the socioeconomic disparities and living conditions. ${ }^{4}$ Healthcare resources are scarce and surge capacity weak. ${ }^{5}$ Vulnerabilities (predominance of unstructured employment, limited employment security and health protection, inadequate health awareness and care access) remain high and underassessed. ${ }^{4}$

With a population of $\sim 1.4$ billion, India's response to COVID-19 directly affects $17.7 \%$ and $21.8 \%$ of the global and LMIC populations, respectively. ${ }^{3}$ This paper aims to provide

\section{Summary box}

- Low-and-middle-income countries (LMICs), where $85 \%$ of the world's population reside, need contextrelevant approaches.

- We analysed India's (an LMIC) initial response to the pandemic (from 17 January to 20 April 2020).

- India's variegated epidemiological, sociopolitical and systemic vulnerabilities make its pandemic response complex.

- India could leverage pre-existing legislative provisions to adopt a collective combat, with states taking the lead with support from the union government; the pre-emptive stringent nationwide lockdown had benefits as well as uncovered vulnerabilities.

- Insights from India's initial response will help in response preparedness and planning for future pandemics, especially in the LMIC context.

a descriptive account of India's response to the pandemic in the initial months, that is, from 17 January (when it issued its first travel advisory for COVID-19) until 20 April (initiation of graded relaxation of the nationwide lockdown). We build the analysis on India's LMIC context.

\section{COLLATION OF INFORMATION \\ Setting}

India has a semifederal democratic governance system. The Constitution of India vests the responsibility of 'health' in its states, and that of preventing the spread of infectious diseases from one state to another concurrently with the Government of India (GoI) and the states. ${ }^{6}$

\section{The GRID COVID-19 Study Group}

Our group $(n=55)$ has members located across 40 institutions in India (21 of 28 states and 3 of 8 union territories (UTs). These include teaching faculty $(n=47)$ and residents $(n=3)$ in departments of community medicine in medical schools, full-time public health researchers $(n=3)$, monitoring and evaluation expert $(n=1)$, 


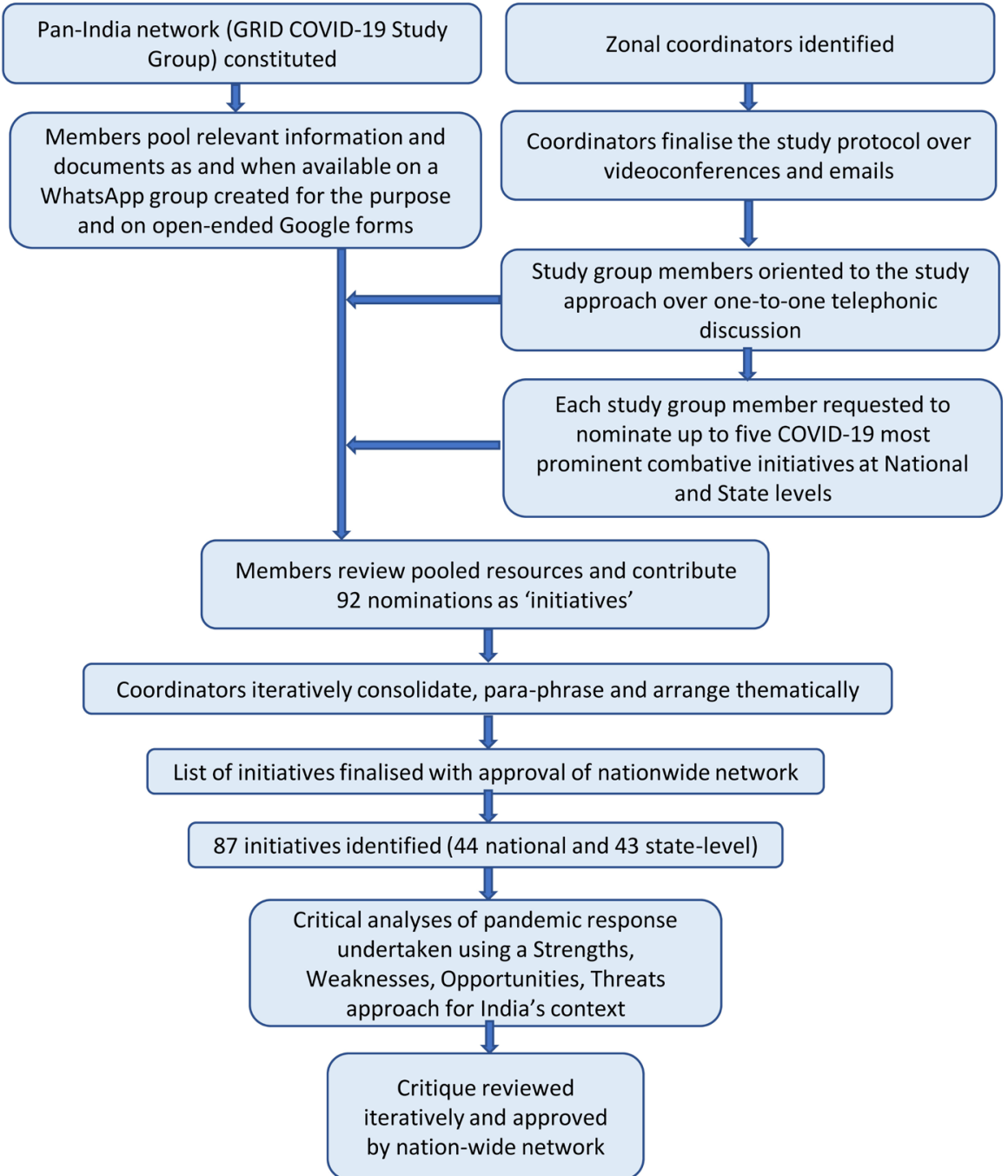

Figure 1 Study flow diagram. GRID, Generating Research Insights for Development.

and a pharmacoepidemiologist $(\mathrm{n}=1)$ in academic research organisations. The members were identified based on their engagement in COVID-19 pandemic containment in various capacities (as programme advisors, implementers, members of rapid response teams, researchers) in respective states/UTs and at the national level. The group kept track of COVID-19 developments in respective and neighbouring states and UTs.

\section{Data sources}

The group members pooled government communications (eg, public orders, circulars, advisories, guidelines, press releases, updates on official websites), guidance documents from stakeholder constituencies (eg, professional associations, local authorities), and excerpts from leading national and local newspapers (on open-ended Google Forms), social media resources ('MyGov Corona Newsdesk' on the Telegram app) and relevant reports by sharing them to a common group created on WhatsApp (a popular social media app used on mobile devices).
For data on cases (number of active cases, recovered/ discharged, deceased and migrated, at the national and state level), we archived information from the Ministry of Health and Family Welfare (MOHFW; mohfw.gov.in) every day between 22:00 and 23:59 India standard time to capture updated statistics.

\section{Quality check and archiving}

A group of nine coordinators provided oversight. Two coordinators (ArM and $\mathrm{SB}$ ) curated the repository by removing duplicate documents and verifying authenticity through triangulation from multiple sources, including government documents and websites. Data were archived chronologically according to date and with labels for easy retrieval.

\section{Synthesis and analysis}

We designed a timeline of key events related to the pandemic in India by sequencing major government circulars and interventions. Between 21 and 26 April, the group members reviewed the repository of resources 


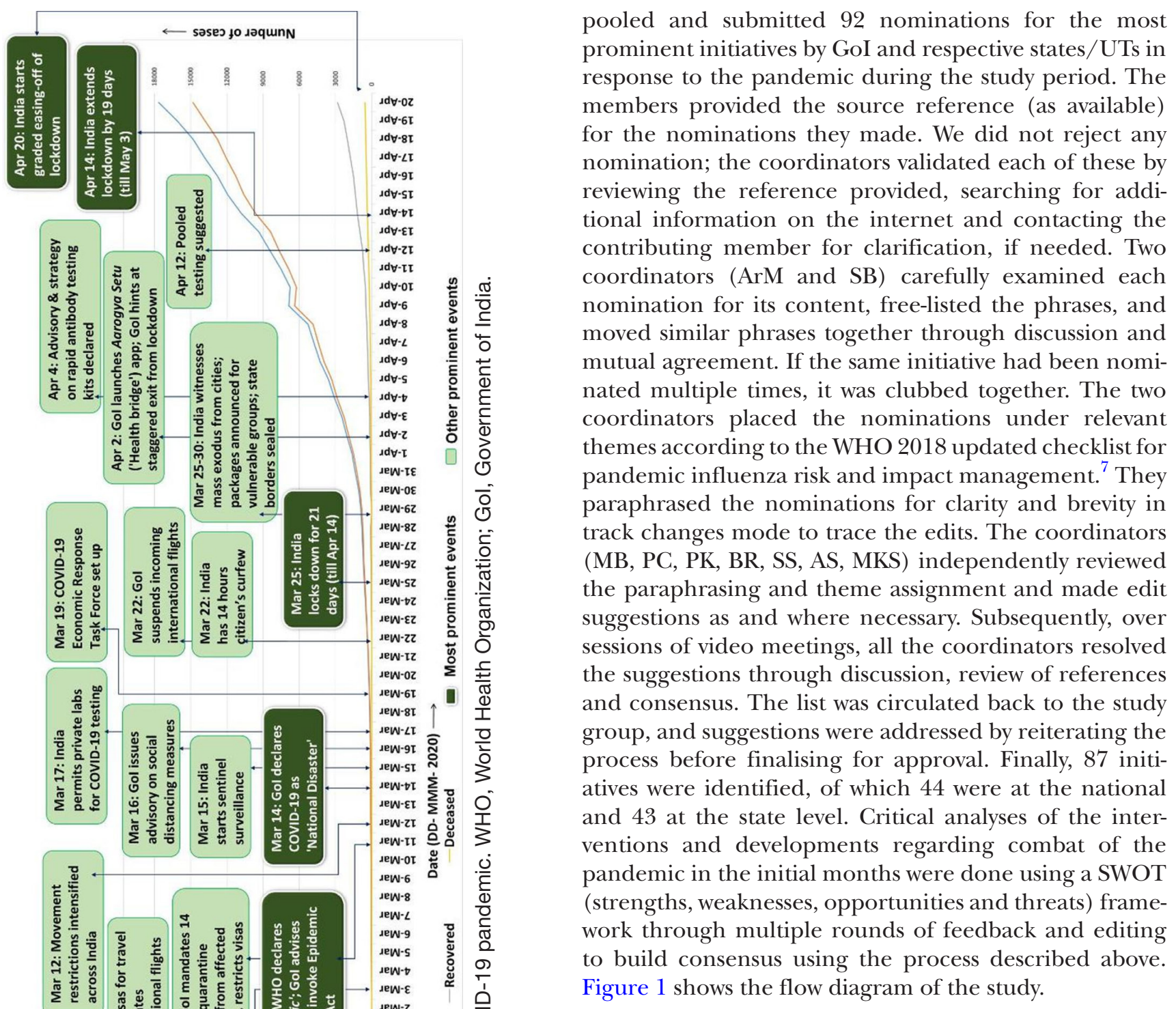

\section{INDIA'S INITIAL RESPONSE}

Figure 2 presents a timeline of events, and box 1 provides a list of initiatives undertaken in the initial 3 months by the union, and states and UTs to combat the pandemic.

\section{Preparing for an emergency}

India reported the first three cases between 30 January and 2 February-all returnees from Hubei Province, China. After a hiatus through February, cases started increasing from early March. Starting mid-January (17-21 January) through mid-March, India issued advisories against nonessential international travel and suspended pre-existing visas in a graded manner at its ports of entry: air, sea and land. ${ }^{8}$ By mid-March, states/UTs had started prohibiting mass gatherings and levying curfew in selected areas. The public were advised to observe social distancing, hand hygiene and cough etiquettes, and to stay at home. On 22 March, GoI called for a voluntary citizens' curfew. The country went under a 21-day complete lockdown on 25 March (with just about 3.5 hours' notice on 24 March). ${ }^{9}$ The lockdown was extended thereafter. 
Box 1 List of some of the prominent initiatives/interventions in India in response to the COVID-19 pandemic (based on WHO 2018 checklist for pandemic influenza risk and impact management) ${ }^{7}$

1. Preparing for an emergency.

1.1. Planning coordination and resources.

- Gol constituted 11 empowered groups and a coordination group for pandemic response.

- States formed multidisciplinary taskforces and advisory panels.*

- Gol solicited public and private donations for PM's National Relief Fund.

- Gol launched the PM CARES Fund-individuals, PSUs and corporates contributed funds.

- India proposed the creation of SAARC COVID-19 Emergency Fund to neighbouring nations.

1.2. Legal and policy issues.

- Epidemic Diseases Act, 1987 invoked —international travel suspended; states gained increased administrative power, started locking down before declaration of a nationwide lockdown.*

- Disaster Management Act, 2005 invoked—Gol declared the pandemic as a 'national disaster', increased fund access to states and UTs; nationwide lockdown implemented from 25 March.

- Section 144 of Criminal Procedure Code, 1973 activated prohibiting public assembly of $\geq 4$ people.*

- States drafted respective COVID-19 pandemic regulations. *

1.3. Ethical issues.

- ICMR released the national guidelines for ethics committees reviewing biomedical and health research during COVID-19 pandemic by second fortnight of April 2020.

1.4. Risk communication and community engagement.

- Religious leaders, celebrities and social influencers engaged in social mobilisation.

- Caller tunes set in regional languages on prevention of SARS-CoV-2 and stigma.

- MOHFW, states released information materials and daily updates on COVID-19 situation.

- MOHFW created a central repository of SOPs, guidelines and resources developed by it.

- MOHFW and state representatives conducted regular periodic press briefings; Press Information Bureau, Gol made media releases actively.

1.5. Points of entry.

- Airports: travel advisories issued against non-essential travel to high-risk countries (17 January); screening of passengers coming from high-risk countries scaled up (17 January); pre-existing visas suspended; universal screening initiated (4 March); mandatory 14-day quarantine on arrival (11 March); Indian citizens evacuated from affected countries.

- Sea ports: in sync with International Health Regulations, 2005, the Ministry of Shipping issued advisories, quarantine and entry protocols (28 January).

- Land checkpoints: immigration checkpoints with neighbouring countries shut down; cross-border passenger train and bus services, and border local markets suspended; those with influenza symptoms or travelling from afflicted countries quarantined.

1.6. Travel restrictions.

- International travel advisories issued against non-essential travel from January.

By mid-March, most pre-existing visas suspended.

- International and domestic commercial flights prohibited.

- During nationwide lockdown, passenger trains suspended, mass movement restricted, and interstate and interdistrict borders* sealed.

2. Surveillance, investigations and assessment.

2.1. Laboratories.

- Testing scaled out from NIV to 51 ICMR centres, with additional 50 collection centres (16 March).

- Private labs roped in; existing facilities upgraded.

- Sample collection kiosks and mobile COVID-19 testing vans set up.*

- 'Made-in-India' coronavirus testing kits released to the market (end of March).

2.2. Surveillance, outbreak investigation and monitoring.

- ICMR centres checked random samples (symptomatic but without travel history to outbreak zones) for community transmission between 15 and 29 February (20 samples in total), and then from 16 March (each of the 51 centres tested 10 samples each week).

- ICMR estimated proportion of COVID-19 cases based on SARI and ILI sentinel surveillance.

- IDSP network leveraged for community-based surveillance.

- Testing criteria revised as per need for information and evolution of the pandemic.

- Private sector engaged for sentinel surveillance.

- Over-the-counter sales of cold and influenza medications monitored.

- Drones used for monitoring sanitisation, public movement and surveillance. *

- Call data records used to track COVID-19 clusters and those returning from 'super-spreader' events. *

- Citizens under home quarantine tracked with a tool, the 'COVID-19 Alerting Tracking System'.*

- Mobile app released for reporting SARI by private providers.*

- Cluster containment strategies adopted to assess and counter risk.

- Village taskforce constituted to monitor and report COVID-19 cases and enforce lockdown. *

- Civil society organisations helped in identifying hotspots and in mitigating stigma.*

- Contact tracing and surveillance undertaken with engagement of community medicine experts and other personnel of medical colleges.* 


\section{Box 1 Continued}

2.3. Risk and severity assessment.

- Fever and influenza clinics set up at health facilities for risk assessment and triage.

- Active and passive surveillance intensified to identify geographical hotspots and suspects.

- Front-line workers conducted home visits to identify and inform individuals with comorbidities.*

- Rapid response teams constituted at national and state levels.

- Aarogya Setu mobile app launched for risk communication and tracking. ${ }^{15}$

- Released plan for graded relaxation of lockdown from 20 April using colour zoning (based on case load and case doubling rates) for surveillance and cluster containment strategies.

3. Health services and clinical management.

3.1. Health services.

- Health service continuity: US\$2 billion emergency financial package for healthcare by Gol; free-of-cost testing and treatment for COVID-19 under the national universal health insurance scheme ('PM JAY'); patients with chronic diseases given medicine refill stock for 3 months in advance; ${ }^{*}$ home delivery of 1 month's antituberculosis medicines*; amendment of telemedicine practice guidelines by Gol (24 March); attacks on HCWs engaged in COVID-19 response made promptly punishable under law*; PPE given to HCWs with a guidance plan on reuse*; rationing of HCWs engaged in COVID-19 care (stand-by staff, staff rotation).*

- Facilities: military hospitals engaged in preparing dedicated COVID-19 facilities, including ICUs; upgrading/modifying existing public hospitals and private hospitals as COVID-19 hospitals*; converting hotels, train coaches, sports stadiums, schools and so on into isolation/quarantine centres.*

- Personnel: additional healthcare personnel appointed on ad-hoc basis; release of advance/increased salaries for HCWs engaged in COVID-19 response*; deployment of medical and paramedical students in screening, contact tracing and other services*; more than thirty thousand doctors (including retired, armed forces, private doctors) volunteered in response to Gol request; volunteers deputed in service delivery to elderly, differently abled, children and transgenders*; teams engaged in community activities provided with non-contact thermal screeners, masks and gloves*; accident insurance for HCWs and front-line workers involved in COVID-19 response.*

- Essential medicines, supplies and medical devices: India's car makers helped to produce low-cost ventilators, masks and protective equipment; Gol with state government increased production and procurement of PPE, N95 masks and ventilators; Ministry of Textiles, MSMEs and workers' (eg, weavers) association increased production of masks; price of masks (two-ply/three-ply surgical masks, N95) and hand sanitisers capped by Essential Commodities Act, 1955; early delivery of medicines and medical equipment was incentivised*; military transport fleet engaged in logistics support; civil society organisations helped in delivery of public healthcare/hygiene services. ${ }^{*}$

- Managing mortality: MOHFW released guidelines on dead body management. Guidelines issued for relatives and crematoria staff involved in final rites.* $^{*}$

3.2. Clinical management.

- Treatment and patient management: stock appraisal of drugs, PPE, critical care infrastructure and demand forecasting*; SOPs by apex medical centres and disseminated (through webinars and website) on various aspects of patient management (triage, testing, admission, discharge and so on); hospitals conducted mock drills for emergency response for handling COVID-19 cases*; hydroxychloroquine endorsed for COVID-19 prophylaxis and treatment and declared as Schedule $\mathrm{H} 1$ drug, thus restricting its over-the-counter sale; influenza desk made mandatory at all health facilities*; online trainings offered to increase clinical management capacity among personnel.

- Infection prevention and control: administrative procedures eased for procuring PPE, masks and sanitisers; work distribution and PPE matched to work profile*; SOPs prepared for hospital infection prevention and control-institutions adapt/prepare SOPs as per local needs; crowd management in hospitals to minimise mixing of those with and without COVID-19 risk profile.

4. Preventing illness in the community.

4.1. Non-pharmaceutical countermeasures.

- Personal interventions: IEC initiatives for spreading awareness on social distancing, hand hygiene, cough etiquettes, movement restriction and stigma mitigation; incentive for self-registration and home quarantine for those returning from international travel; time-stamped route maps of each patient with COVID-19 released to the public (for general awareness)*; videos hosted on MOHFW website on making of masks at home, appropriate method for donning and removing them, and on hand hygiene; launch of self-assessment interactive apps for COVID-19*; governments posted guidance on preventive measures (dos and don'ts) on official web portals and in print and social media for wider dissemination.

- Community interventions: shutting down public places, for example, offices, schools, malls and so on; advisories for work-from-home and shelterin-place; nationwide lockdown (from 25 March); release of prisoners to decongest jails*; waiving off school examinations*; wearing masks made mandatory during outings*; floor marking for social distancing in queues; hand sanitisers and thermal scanners at shop, residential society and office entrances.

5. Maintaining essential services and recovery.

5.1. Essential service continuity.

- Gol recommended states and UTs to use the State Disaster Response Fund for providing food and shelter to migrant workers during the lockdown period.

- Shrines volunteered to offer cooked meals and share costs incurred by government for surge.*

- RBI (India's central regulatory bank) took initiatives to expand liquidity.

- Gol announced US\$22.6 billion relief package for poor, rural and migrant population (Prime Minister's Poor Welfare Scheme; PM GKY).

- Increased share and subsidies on rations distributed through the public distribution system.

Disbursement of advance/increased pensions for retirees, differently abled, widows and elderly.*

Subsistence amounts given to construction workers. * 


\section{Box 1 Continued}

- Doorstep delivery of daily essentials (eg, groceries, vegetables, medicines) during lockdown.*

- Movement restriction waivers provided for limited hours of the day to buy essentials.*

- Internet data purchase allowance for students to continue online classes.*

- Vigilance tightened against price inflation and hoarding/black marketing of general commodities.

- Mobile automated teller machines parked near residential apartments. *

5.2. Recovery.

- Helplines set up and online counselling sessions organised for mental health conditions.

- Relief camps and helpline numbers for stranded migrants with help from civil society organisations.

- RBI advises banks to offer 3-month moratorium on loan instalment payments by individuals.

6. Research and development.

- Indian firms initiate work on 'vaccine candidates', some along with international collaborations.

- Request for proposals on COVID-19-related research from major research councils and institutions.

- Major research labs engaged in diagnosis, vaccine development and disease prediction modelling.

- Biotechnology/bioengineering labs suggested low-cost ventilators and equipment for surge.

- Leading scientific journals in India worked towards coming up with special issues on COVID-19.

- Approval and market release of first Made-in-India COVID-19 testing kit (25 March).

- India joined WHO Solidarity Trial to develop therapy for COVID-19 (27 March).

- Private hospitals permitted to initiate trials with convalescent plasma therapy (19 April).

- ICMR constituted thematic taskforces for exploring research avenues.

*Initiative undertaken by some states/UTs.

Gol, Government of India; HCWs, healthcare workers; ICMR, Indian Council of Medical Research; ICU, intensive care unit; IDSP, Integrated Disease Surveillance Programme; IEC, Information, education and communication; ILI, Influenza-like illness; MOHFW, Ministry of Health and Family Welfare; MSMEs, micro small and medium enterprises; NIV, National Institute of Virology, Pune; PM, Prime Minister; PM CARES, Prime Minister Citizen Assistance and Relief in Emergency Situations; PM GKY, Pradhan Mantri Gareeb Kalyan Yojana; PM JAY, Pradhan Mantri Jan Arogya Yojana; PPE, personal protective equipment; PSUs, public sector undertakings; RBI, Reserve Bank of India; SAARC, South Asian Association for Regional Cooperation; SARI, severe acute respiratory infections; SOPs, standard operating procedures; UT, union territory.

\section{Surveillance, investigation and assessment}

Community-based surveillance activities were scaled up across India by end of March. The number of testing and collection centres was increased, testing criteria were extended, and private laboratories were engaged. On 4 April, free-of-cost testing and treatment for COVID-19 was mandated under the national universal health insurance scheme (Pradhan Mantri Jan Arogya Yojana), further expanding testing outreach. ${ }^{10}$ Geographical areas with higher number of cases were labelled as hotspots, and aggressive cluster containment strategies were adopted. Areas were earmarked as red (hotspots), yellow and green zones in descending order of case load; while stringent restrictions continued in the red zones, others were conditionally eased from 20 April. ${ }^{11}$ Some states extended the lockdown without relaxation.

\section{Health services and clinical management}

The GoI and state governments scaled up provisions for institutional quarantine and isolation centres and COVID-19 hospitals (beds with oxygen and critical care services). Ventilators and personal protection equipment were consigned from vendors in the country and abroad. Training of personnel in the care of COVID-19 suspects and patients was undertaken aggressively. A series of guidelines and standard operating procedures were released by the MOHFW, GoI and the country's apex medical institutions (eg, All India Institute of Medical Sciences, New Delhi) and disseminated as webinars and video modules. ${ }^{12} 13$ Private providers and facilities were identified and mobilised for institutional surge preparedness. Volunteering was solicited from healthcare professionals. Telemedicine guidelines were launched on 25 March to facilitate access to medical consultations. ${ }^{14}$ The Aarogya Setu (Health Bridge) app was launched on 2 April and made mandatory in offices and public places to enable dissemination of advisories, best practices and tracking. ${ }^{15}$

\section{Preventing illness in the community}

Non-pharmaceutical interventions were targeted at the individual and the community. These were mainly through public health communication and implementation of social distancing, movement restriction and wearing of mask in public places. The lockdown limited people's exposure to the virus.

\section{Maintaining essential services and efforts for recovery from the pandemic}

Consultations between the union and states prior to and during the lockdown were undertaken for stringent implementation of restrictions while minimising disruption of essential goods and services. The Ministry of Home Affairs, GoI issued guidelines on 24 and 25 March specifying the services that were exempt from the lockdown restrictions. ${ }^{9}$ In addition to health and police services, the list included regulated financial markets, and staff engaged in petroleum products, supply chain, cargo, customs, mining, forest, and social welfare department, and others. ${ }^{9}$ Interventions to mitigate hardship 
Box 2 Perceived strengths, weaknesses, opportunities and threats in the Indian context during the initial months of combating the COVID-19 pandemic (definitions adapted from WHO documents) 2627

Strengths: factors intrinsic to India that position it towards a strong performance against the COVID-19 pandemic.

- Governance: semifederal, democratic and decentralised governance; consultative decision-making processes (eg, taskforces); multiple channels of public communication; strong engagement with development partners.

- Existing legislative mechanisms (eg, the Epidemic Disease Act, 1897; the Indian Ports Act, 1908; the Drugs and Cosmetics Act, 1940; the Essential Services Maintenance Act, 1968; the Disaster Management Act, 2005): if invoked, these allow special administrative powers to the government.

- Programmatic outreach: allows targeted delivery of entitlements to the vulnerable (eg, the public distribution system for food security, zero-balance and minimal documentation bank accounts for direct cash transfer, social security schemes, commitment to universal health coverage and so on).

Weaknesses: factors intrinsic to India that impede performance and need change/investment.

- Fragile and chronically underfunded health system: poor infrastructure and tertiary care capacity; inconsistent supplies; data challenges (eg, quality, timeliness, adequacy); limited engagement of private sector; absent/inadequate health insurance cover.

- 'Missing millions' (the homeless migrants, illegal immigrants, people in humanitarian crises, disaster-ravaged groups): although not adequately assessed, the numbers are substantial.

- Limited institutional preparedness for managing pandemics: India has managed recent infectious disease outbreaks, but protocols (eg, for public health emergency management protocols, public-private collaboration, research engagements) are in evolution.

Opportunities: prospects in the current COVID-19 context that could be exploited for effective combat of COVID-19.

- A better understanding of SARS-CoV-2 and COVID-19: scientific evidence on disease management, prevention and containment is increasingly available from January 2020.

- Favourable age pyramid: only $8.5 \%$ of India are over 60 years of age,majority are under 30 . A young population may have a lower risk of mortality from COVID-19 and help in faster economic recovery.

- Indigenous capacity: India's large pharma, research and development, and the information technology industry can contribute to global efforts (vaccine development, delivery, diplomacy).

- Wide reach of telecommunications and social media: makes risk communication faster and with outreach for public engagement.

- Availability of deployable health human resources: for example, community medicine and public health professionals for technical support, physicians from the Indian system of medicine for primary care coverage, huge network of community-based workers (especially in states with weaker health infrastructure) for outreach, and private laboratories, hospitals and organisations for service scale-out; expansion of tertiary healthcare institutions in recent times.

Threats: elements in broader environment that could endanger/inhibit progress in the combat of COVID-19.

- Huge population size and LMIC context: India's vast population, poor living and health access conditions, and heterogeneous epidemiological profile increase the risk of spike in COVID-19 cases and of overwhelming system capacity.

- Economic stagnation: growth of India's economy has been slower, of late-could limit fiscal space for aggressive countermeasures against the pandemic.

- Limited surge capacity for testing and institutional care (eg, critical care experts, infrastructure, access, space for isolation); inadequate supply of PPE.

- Implementing prolonged restriction will impede essential services, lead to loss of livelihoods (job profiles inconducive to working from home; farmers must protect the spring harvest) and cause adverse economic impact. The strategy for exit from lockdown is complex.

- Sociobehavioural complexities: risk of some people flouting preventive directives, stigmatisation, misinformation and rumour mongering, violence against healthcare workers and police, hoarding of essentials (PPE, medicines, sanitisers, groceries) and upsurge in psychosocial health issues (eg, depression, alcohol withdrawal, domestic violence).

LMIC, low-income and middle-income country; PPE, personal protective equipment.

among the poor and vulnerable were introduced by the GoI and state governments. ${ }^{16}$

\section{INSIGHTS}

\section{Understanding the Indian context for pandemic response}

India presents a mix of inherent strengths and weaknesses in combating the pandemic (box 2). Thereupon, the COVID-19 pandemic uncovers some perceivable opportunities and threats. An appreciation of these facets will help the reader understand the context and its influence on India's response.

\section{Combating risk of importation of the virus}

'Nobody can be fully prepared to a pandemic'. ${ }^{1}$ India also could have benefited from even further pandemic response planning and preparedness. The country had its first case on 30 January. Between January and early March, India focused almost exclusively on minimising the risk of importation. In hindsight, it seems that aggressive surge preparedness could also have been undertaken in the meanwhile (especially in February) given that the virus had originated from an immediate neighbouring country and that WHO had already declared it as a 'Public Health Emergency of International Concern' on 30 January. ${ }^{17}$ The graded border control approach using selective screening and travel restrictions in January to February, leading to universal screening, visa suspensions and mandatory quarantine in March, could not adequately counter the risk of importation. Moreover, relying on thermal scanning was not infallible as several cases were afebrile/asymptomatic. Cases started increasing rapidly in early March. Containment and surge efforts followed subsequently (around mid-March). 
Box 3A Insights from India's initial response (17 January-20 April) to combat the COVID-19 pandemic: strengths in India's response

- Conspicuous political commitment: union and state governments and political parties mostly came together supporting one another during the crisis.

- Visa restrictions: India experienced limited importation from countries for which travel advisories were restrictive. India suspended most of its existing visas from 15 March. ${ }^{28}$

- Initial engagements: stakeholder constituencies (governments, private sector (profit, non-profit), civil society, communities and individuals) were responsive to the COVID-19 scare despite the delay during the earliest months (January-February) and instituted preventive measures in support of one another.

- Legislative frameworks enabled administrative leadership: invocation of the Epidemic Diseases Act, 1897 (on 11 March) and the Disaster Management Act, 2005 (on 14 March) allowed further administrative power and fund access to Gol and state governments. Support for nationwide lockdown shows collective leadership from stakeholder constituencies.

- Community-based surveillance: in the absence of adequate testing resources, India scaled up its house-to-house mass surveillance and sensitisation efforts through syndromic approaches, leveraging existing integrated surveillance systems and its large network of front-line workers.

- Programme outreach helped in targeting the entitlements: pre-existing social welfare programmes, internet banking services and Jan Dhan bank accounts (zero-balance bank accounts for the poor) facilitated disbursement of entitlements to targeted beneficiaries with speed and minimal pilferage. ${ }^{23}$

- ICMR supported Gol with setting up the network of labs for testing and serosurveillance, and by setting up thematic taskforces (to plan, implement and monitor guidelines). It also advised on treatment protocols based on upcoming local evidence.

- States have the potential to innovate; the chance of success increases with prior experience in managing disasters and outbreaks: while Gol facilitated the combat of the pandemic, states rapidly innovated, co-learnt and co-adapted various innovations with local effectiveness. Examples include the following:

- Aggressive community containment after an outbreak (Bhilwara model, Rajasthan).

- Convergence in an urban setting (Vishakhapatnam in Andhra Pradesh).

- Community-based surveillance with high coverage despite difficult mountainous terrain (the Himachal Pradesh experience of engaging front-line health workers, and the Jammu and Kashmir experience of leveraging technology).

- The ethnic tribal communities in the North-East demonstrated how community vigilance and local systems of governance could coexist with formal epidemiological surveillance.

- Odisha, one of the most resource-constrained and disaster-ravaged states in India, emerged as a 'first mover' in pandemic preparedness with its adeptness at managing natural disasters.

- Kerala was able to 'bend the curve' (number recovered > number tested positive each day; Kerala model) through system-wide effort across a strong health system; the state has successfully combated the Nipah virus outbreak and a severe flood in the recent past.

- Engagement of district administration with local medical colleges for patient care and surveillance guidance (in some districts): this helped in techno-administrative convergence with contextualisation and in the mobilisation of human resources.

ICMR, Indian Council of Medical Research; Gol, Government of India.

Meanwhile, COVID-19 was declared a pandemic by WHO. ${ }^{17}$ Worsening situations internationally, such as in Italy, UK and Iran, added to India's anxiety.

Since mid-March, India has acted swiftly to stem the rising cases of COVID-19. Existing legislative provisions (prominently the Epidemic Diseases Act, 1897 and the Disaster Management Act, 2005) and semifederal governance structure provided due leverage. India thus mobilised resources and provided administrative flexibility to state governments to utilize the disaster funds, enabling contextual action. As a consequence, states could implement mass movement restrictions, access funds, mandate citizens into institutional quarantine and isolation, and regulate industries (implement work-from-home advisories). Alongside, GoI suspended visas and declared a nationwide lockdown.

\section{Experience with 'pre-emptive' nationwide lockdown}

The first phase of the lockdown (25 March-14 April) in India was unlike any other country in scale, timing and stringency. The lockdown gave India time for surge preparedness especially in testing capacity and institutional healthcare provisions. ${ }^{18}$ People also accepted and supported the stringent restrictions (pandemic response may evoke strong support or protests in democratic settings). Prevention, containment, impact mitigation and recovery efforts gradually became concurrent. Administrative decision-making capacity was increasingly strengthened (up to subdistrict levels). To compensate for insufficient testing capacity, the country engaged its massive network of community-based workers and undertook aggressive community-based surveillance, contact tracing and cluster containment strategies. ${ }^{19}$ Official channels of communication to stakeholders gradually became structured and consistent, allaying spread of misinformation. Meanwhile, aggressive media coverage increased public awareness.

In the absence of robust epidemiological data and amidst predictions of rapid increase in COVID-19 cases, India locked down 'pre-emptively' and 'nation-wide' at extremely short notice. The lockdown slowed down the spread of infection: the case doubling time (7-day moving average) on 25 March was 3.4 days and on 19 April was 6.2 days; however, the number of cases kept increasing. ${ }^{20}$ On 24 March, when India declared lockdown, it had 564 cases and 10 deaths; on 20 April, when graded relaxation 
Box 3B Insights from India's initial response (17 January-20 April) to combat the COVID-19 pandemic: facets for further strengthening

Aspects specific to the COVID-19 pandemic.

- Countering risk of importation: India's graded checks at airports, sea ports and land borders (January-March 2020) varied in stringency, criteria and timing. Universal screening and mandatory quarantine at airport arrivals were initiated late (in March). Just 19\% of air passengers arriving between 17 January and 23 March could be screened. ${ }^{29}$ Some passengers dodged advisories (self-declaration of symptoms, mandatory self-quarantine).

- Surge preparedness: India had limited surge preparedness in February. Limited testing capacity (number and coverage), restrictive testing criteria and cautious engagement with private sector impeded initial 'test-isolate-treat' efforts. Frequent modification of criteria for testing, quarantine and isolation required repeated unlearning and relearning. States were able to ramp up quarantine and isolation facilities but were relatively underresourced for beds with oxygen and critical care support.

- Leveraging IT: despite its huge IT capacity and potential to generate indigenous big data, India could not adequately leverage technology for surveillance or data analytics. The Aarogya Setu app (for tracking and public messaging) was criticised for gaps in data security. ${ }^{15}$

- Data integration, reconciliation and access: while the Indian Council of Medical Research and the Ministry of Health and Family Welfare released data summaries on a daily basis from late March, the two initially had mismatch and needed reconciliation. The National Centre for Disease Control could not publish its weekly outbreak reports (from routine influenza syndromic surveillance) since February $2020{ }^{30}$ Validated multi-jurisdictional and sectoral information was unavailable and impeded research.

- Preventing potential super-spreader events: during the pandemic, outbreaks were linked to mass congregations that had been organised in violation of administrative restrictions. Contact tracing and isolation-quarantine activities had to be surged up impromptu and sustained thereafter but not all attendees could be traced back to the community.

- Quality of quarantine and isolation facilities: India's quarantine facilities were criticised for lack of civic amenities and hygiene and for overcrowding. ${ }^{31}$ Some people resisted/escaped institutional quarantine-isolation; family members were anxious. ${ }^{32}$

- Lockdown: The 'pre-emptive' nationwide lockdown implicated fiscal 'sacrifice' and collateral impact (impaired routine health services, loss of livelihoods, massive reverse migration, mental health challenges). 'Cash injections' by the government to mitigate hardship were inevitable yet inadequate.

- Managing the 'infodemic': information overload (both correct and wrong), media attention, wide access to social media and deep penetration of tele-networks enabled fast dissemination. Alongside increasing awareness, public anxiety, stigmatisation and rumour mongering were also seen.

Aspects that go beyond the COVID-19 pandemic.

- Building on experience: India's initial response to COVID-19 reiterates gaps it witnessed during the 2009 H1N1 (swine influenza) pandemic, that is, screening limited to major airports, urban-centric approach, limited diagnostic centres, lack of intensive care capacity and access. ${ }^{33}$ India needs proactive preparedness given recent outbreaks (eg, Nipah and Zika virus diseases, acute encephalitis syndrome). India's Influenza Pandemic Preparedness Plan is of 2009; the December 2019 version is awaited in the public domain.

- Decision-making for public health action: committees constituted initially for the pandemic were led by experts beyond epidemiology and public health disciplines. Decisions were inconsistently based on evidence. Having an exclusive public health cadre could have made processes more efficient.

- Gaps in the health sector cannot be corrected rapidly: India's health system has traditionally been underfunded year-on-year (allocation in 20192020 annual union budget $\sim 1.4 \%$ of gross domestic product).

IT, information technology.

was allowed, there were 17656 cases and 559 deaths. ${ }^{12}$ By 20 April, cases had been identified in 31 of 36 states and UTs and in 402 of 718 districts. ${ }^{21}$ Twenty districts accounted for over half the cases and two-thirds deathsthese were among the most urbanised, affluent and industrialised districts in the country. ${ }^{21}$ States and UTs showed variegated epidemiological curves (online supplemental figure $1 \mathrm{~A}$ and $\mathrm{B})$.

Contextual opportunities, for example, a relatively young population, accruing global understanding of the virus and the disease, and capacity for generating indigenous research evidence, remained underutilised as India went into a very stringent lockdown. The lockdown uncovered vulnerabilities and triggered cascading effects across sectors and industries. ${ }^{22}$ The economy which was already ailing got further disrupted. The impact was highest at the 'base of the pyramid' (lowest socioeconomic strata) of the Indian society. People lost jobs and livelihood; reports of hardship, stress, anxiety and domestic violence came up. GoI and state governments rolled out initiatives to mitigate hardship among the vulnerable using preexisting institutional mechanisms and programmatic outreach (eg, validated bank accounts for direct benefit transfer, network of public distribution system for food security, and others). ${ }^{23}$ They were assured of food and shelter. Nevertheless, the initiatives were inadequate to check reverse migration. Millions of workers migrated back home in the absence of any source of continued livelihood. The 'reverse migration' was frequently on foot and in overcrowded conveyances, thus threatening to push the virus deeper into rural India where pandemic preparedness was further weak. ${ }^{24}$ Given its ramifications and potentially long-term impact (including that related to stigma), strategising exit from the lockdown and subsequent recovery of communities from the pandemic was challenging.

\section{Critical analyses for practice and preparedness}

Given the dynamicity of India's response, our current account may be non-exhaustive, but captures information 
from across the country. Some of the approaches undertaken by India seemed to have worked out in favour, while some needed better planning. We have summarised the insights from India's response to the pandemic in the initial months in box $3 \mathrm{~A}$ and $\mathrm{B}$.

\section{CONCLUSION}

Within the initial few months, India could mobilise collective leadership and action, and secure public cooperation to undertake stringent combative measures against the pandemic. Apart from isolated incidents, there was minimal public resistance to the stringent nationwide movement restriction norms. Experience from India suggests that the LMIC context could be volatile, ambiguous and uncertain, and hence engaging with the community and other stakeholders is a critical facilitator. It also highlights that LMICs have complex socioepidemiological ecosystems with refractory vulnerabilities that could compromise the sustainability and impact of stringent measures. Combative response to pandemics in such settings is likely to be improvisatory and broad-based (less precise) in the absence of a structured pandemic response plan. Stringent measures must be carefully weighed against alternatives and undertaken with concurrent mitigation and recovery initiatives. A contextualised and updated pandemic response plan with dynamic decision support systems could help in ensuring timely and structured response to national and international epidemiological triggers (scarce resources need efficient planning). Unfortunately, most LMICs either do not have a national plan for pandemic preparedness and risk management or have one that has not been updated recently. ${ }^{25}$ COVID-19 pandemic combat strategies and experience vary worldwide. India is relatively better resourced as compared with other LMICs in several aspects, and hence some of the Indian experience may not be readily extrapolatable to other LMICs. Nevertheless, India shares several challenges and vulnerabilities typical of LMICs (eg, high population, resource constraints, socioeconomic milieu). Going forward, countries and especially LMICs (including India) will find the Indian experience variously relatable for planning response against the current and future pandemics, despite resource inconsistencies, while also appreciating that each country has its unique contextual strengths and weaknesses to account for and leverage.

Acknowledgements We extend our thanks to the families, friends and departmental colleagues who shared information from various sources with us. We also thank Dr Ranadip Chowdhury, Society For Applied Studies, New Delhi, for his help during data analysis and representation. We also extend our earnest thankfulness to the esteemed peer-reviewers for the meticulous review and feedback, and the editor and journal team for the detailed editorial support.

Collaborators GRID COVID-19 Study Group Members: Coordinators: Mohan Bairwa (All India Institute of Medical Sciences, New Delhi, India); Sabyasachi Behera (GRID Council, Bhubaneswar, India); Paragkumar Dhirajlal Chavda (Gujarat Medical Education and Research Society Medical College, Vadodara, Gujarat, India); Praveen Kulkarni (JSS Academy of Higher Education \& Research, Mysuru, Karnataka, India); Archisman Mohapatra (GRID Council, Delhi NCR, India); Balaji Ramraj (SRM Medical College Hospital and Research Centre, SRM Institute of
Science and Technology, Chennai, Tamil Nadu, India); Siddharudha Shivalli (London School of Hygiene \& Tropical Medicine, London, UK); Arvind Kumar Singh (All India Institute of Medical Sciences, Bhubaneswar, Odisha, India); Manish Kumar Singh (Dr Ram Manohar Lohia Institute of Medical Sciences, Lucknow, Uttar Pradesh, India). Members of the nationwide network: Northern India: Ravi Rohilla (Government Medical College \& Hospital, Chandigarh); Bharti Chawla, Sumit Chawla (Pt JLN Government Medical College and Hospital, Chamba, Himachal Pradesh); Rabbanie Tariq Wani (Government Medical College, Srinagar, Jammu \& Kashmir); Rashmi Agarwalla (Hamdard Institute of Medical Sciences and Research, New Delhi); Pranab Chatterjee (Independent Public Health Consultant, New Delhi); Shubhashri Sudhiendra Jahagirdar (The INCLEN Trust International, New Delhi); Madan Mohan Majhi (Maulana Azad Medical College, New Delhi); Harshal Ramesh Salve, Pallavi Shukla, Kapil Yadav, Ramadass Sathiyamoorthy, Nitika Sharma (All India Institute of Medical Sciences, New Delhi); Kaushik Sarkar (Aceso Global Health Consultants Limited - India, New Delhi); Soumya Swaroop Sahoo, Madhur Verma (All India Institute of Medical Sciences, Bathinda, Punjab); North-Central India: Shamshad Ahmad (All India Institute of Medical Sciences, Patna, Bihar); Dewesh Kumar (Rajendra Institute of Medical Sciences, Ranchi, Jharkhand); Anirban Chatterjee (All India Institute of Medical Sciences, Bhopal, Madhya Pradesh); Gaihemlung Pamei (Government Medical College, Haldwani, Uttarakhand); Hariom Kumar Solanki (Government Institute of Medical Sciences, Greater Noida, Uttar Pradesh); Eastern and North-Eastern India: Shashanka Shekhar Chakraborty (Gauhati Medical College, Guwahati, Assam); Gitismita Naik, M Mohan Kumar (All India Institute of Medical Sciences, Raipur, Chhattisgarh); Chinnadurai Aravinda (All India Institute of Medical Sciences, Bhubaneswar, Odisha); Shilpa Karir, Jasmin Nilima Panda (Veer Surendra Sai Institute of Medical Sciences and Research, Burla, Odisha); Jaya Singh Kshatri (Indian Council of Medical Research-Regional Medical Research Center, Bhubaneswar, Odisha); Smrutiranjan Nayak (Kalinga Institute of Medical Sciences, Bhubaneswar, Odisha); Sithun Kumar Patro (Maharaja Krushna Chandra Gajapati Medical College \& Hospital, Brahmapur, Odisha); Shib Sekhar Datta (Tripura Medical College and Dr BR Ambedkar Memorial Teaching Hospital, Agartala, Tripura); Nilanjana Ghosh (North Bengal Medical College \& Hospital, Darjeeling, West Bengal); Pritam Roy (Independent Public Health Researcher, Kolkata, West Bengal); Southern India: Shankar Reddy Dudala (Government Medical College, Kadapa, Andhra Pradesh); Rachana R Annadani, Malatesh Undi (Karwar Institute of Medical Sciences, Karwar, Karnataka); Sudhir Prabhu (Father Muller Medical College, Mangalore, Karnataka); Santosh K Yatnatti (Dr Chandramma Dayananda Sagar Institute of Medical Education and Research, Bengaluru, Karnataka); Rakesh N Pillai (GRID Council, Thiruvananthapuram, Kerala); Antony Stanley (Achutha Menon Centre for Health Science Studies, Thiruvananthapuram, Kerala); Satyanarayana G Konda (Mamata Academy of Medical Science, Hyderabad, Telangana); Western India: Kajal Davara (Gujarat Medical Education and Research Society Medical College, Vadodara, Gujarat); Mihir Prafulbhai Rupani (Government Medical College, Bhavnagar, Gujarat); Anuj Mundra (Mahatma Gandhi Institute of Medical Sciences, Sewagram, Maharashtra); Akhil Dhanesh Goel, Manoj Kumar Gupta (All India Institute of Medical Sciences, Jodhpur, Rajasthan).

Contributors All authors reviewed the drafts, provided critical inputs and agreed on the final version. The coordinators conceptualised and wrote the manuscript.

Funding The authors have not declared a specific grant for this research from any funding agency in the public, commercial or not-for-profit sectors.

Disclaimer The expressed views and opinions in this paper are of the authors and do not necessarily express the views or policies of their organisations and affiliations.

Competing interests None declared.

Patient consent for publication Not required.

Provenance and peer review Not commissioned; externally peer reviewed.

Data availability statement There are no data to share. Circulars and documents cited in the manuscript have been archived by the group and can be provided upon request.

Supplemental material This content has been supplied by the author(s). It has not been vetted by BMJ Publishing Group Limited (BMJ) and may not have been peer-reviewed. Any opinions or recommendations discussed are solely those of the author(s) and are not endorsed by BMJ. BMJ disclaims all liability and responsibility arising from any reliance placed on the content. Where the content includes any translated material, BMJ does not warrant the accuracy and reliability of the translations (including but not limited to local regulations, clinical guidelines, terminology, drug names and drug dosages), and is not responsible for any error and/or omissions arising from translation and adaptation or otherwise. 
Open access This is an open access article distributed in accordance with the Creative Commons Attribution Non Commercial (CC BY-NC 4.0) license, which permits others to distribute, remix, adapt, build upon this work non-commercially, and license their derivative works on different terms, provided the original work is properly cited, appropriate credit is given, any changes made indicated, and the use is non-commercial. See: http://creativecommons.org/licenses/by-nc/4.0/.

\section{REFERENCES}

1 Koçak Tufan Z, Kayaaslan B. Crushing the curve, the role of national and international institutions and policy makers in COVID-19 pandemic. Turk J Med Sci 2020;50:495-508.

2 Emanuel EJ, Persad G, Upshur R, et al. Fair allocation of scarce medical resources in the time of Covid-19. N Engl J Med 2020;382:2049-55.

3 The World Bank. Low \& middle income | Data. Available: https:// data.worldbank.org/income-level/low-and-middle-income [Accessed 28 Apr 2020].

4 Hodgins S, Saad A. Will the Higher-Income country blueprint for COVID-19 work in low- and lower middle-income countries? Glob Health Sci Pract 2020;8:136-43.

5 Hopman J, Allegranzi B, Mehtar S. Managing COVID-19 in low- and middle-income countries. JAMA 2020;323:1549-50.

6 Ministry of Law and Justice, Government of India. The Constitution of India [As on 1st April, 2019]. New Delhi: Government of India Ministry of Law and Justice;, 2019: 1-281.

7 A checklist for pandemic influenza risk and impact management: building capacity for pandemic response. Geneva: World Health Organization; 2018. Licence: CC BY-NC-SA 3.0 IGO. Available: https://www.who.int/influenza/preparedness/pandemic/PIRM_ Checklist_update2018.pdf [Accessed $10 \mathrm{Jul}$ 2020].

8 Ministry of Information \& Broadcasting. India's response to COVID outbreak. In: Press Information Bureau Press Release [Internet]. Available: https://pib.gov.in/PressReleasePage.aspx?PRID=1608727 [Accessed 28 Mar 2020].

9 Ministry of Home Affairs. Government of India issues Orders prescribing lockdown for containment of COVID-19 Epidemic in the country. In: Press Information Bureau Press Release [Internet], 2020. Available: https://pib.gov.in/PressReleasePage.aspx?PRID=1607997 [Accessed 24 Mar 2020].

10 National Health Authority, Ministry of Health and Family Welfare, Government of India. Press release: testing and treatment of COVID -19 now available for free under Ayushman Bharat Pradhan Mantri Jan Arogya Yojana. New Delhi; 2020.

11 Ministry of Health and Family Welfare, Government of India. 170 districts classified as hot spot districts, 207 as Non-hotspot districts where cases have been reported: health Ministry. Available: https:// pib.gov.in/PressReleseDetail.aspx?PRID=1614775 [Accessed $15 \mathrm{Apr}$ 2020].

12 Ministry of Health and Family Welfare, Government of India. COVID-19 India, 2020. Available: https://www.mohfw.gov.in/ [Accessed 20 Apr 2020].

13 All India Institute of Medical Sciences. AlIMS COVID portal, 2020. Available: https://covid.aiims.edu [Accessed 30 Mar 2020].

14 Board of Governors in Supersession of Medical Council of India. Telemedicine practice guidelines. New Delhi, 2020. Available: https:// www.mohfw.gov.in/pdf/Telemedicine.pdf [Accessed $10 \mathrm{Jul}$ 2020].

15 Kodali PB, Hense S, Kopparty S, et al. How Indians responded to the Arogya Setu app? Indian J Public Health 2020;64:S228-30.

16 Ministry of Finance, Government of India. Rs 36659 crore transferred to 16 crore beneficiaries using DBT duing COVID-19 lockdown, 2020. Available: https://pib.gov.in/PressReleasePage.aspx?PRID= 1616022 [Accessed 27 Apr 2020].
17 World Health Organization. WHO Timeline - COVID-19. Available: https://www.who.int/news-room/detail/27-04-2020-who-timelinecovid-19 [Accessed 27 May 2020].

18 Prime Minister's Office. Text of PM's address to the Nation. Press Information Bureau Press Release [Internet]. Available: https://pib. gov.in/PressReleseDetail.aspx?PRID=1614215 [Accessed $15 \mathrm{Apr}$ 2020].

19 Vaidyanathan G. People power: how India is attempting to slow the coronavirus. Nature 2020;580:442. [Correction: 12 April 2020].

20 Ministry of Information and Broadcasting, Government of India. PIB'S DAILY BULLETIN ON COVID-19. Press Information Bureau Press Release. Available: https://pib.gov.in/PressReleasePage.aspx? $\mathrm{PRID}=1616442$ [Accessed 20 Apr 2020].

21 Bhatia S, Devulapalli S. Mapped: The spread of coronavirus across India's districts. livemint. Available: https://www.livemint.com/news/ india/mapped-the-spread-of-coronavirus-across-india-s-districts11587179250870.html [Accessed 11 Jul 2020].

22 The Lancet. India under COVID-19 lockdown. Lancet 2020;395:1315

23 Prime Minister's Office. English Rendering of Prime Minister Shri Narendra Modi's Address to the Nation on 12.5.2020. Press Information Bureau Press Release. Available: https://pib.gov. in/PressReleseDetail.aspx?PRID=1623418 [Accessed 13 May 2020].

24 Sharda S. Lucknow Corona Update: $22 \%$ migrants with Covid-19 symptoms test positive in Uttar Pradesh. Times of India. Available: https://timesofindia.indiatimes.com/city/lucknow/22-migrants-withcovid-19-symptoms-test-positive-in-uttar-pradesh/articleshow/ 75838093.cms [Accessed 12 Jun 2020].

25 World Health Organization. National plans for pandemic preparedness and risk management. Available: https://extranet.who. int/sph/influenza-plan [Accessed 6 Jun 2020].

26 Rajan D. Situation analysis of health sector. In: Schmets G, Rajan D, Kadandale S, eds. Strategizing National health in the 21st century: a Handbook. Geneva: World Health Organization, 2016: 64. https:// apps.who.int/iris/handle/10665/250221

27 World Health Organization. Pandemic influenza preparedness partnership contribution implementation: SWOT analysis results. 2016. Available: https://www.who.int/influenza/pip/benefit_sharing/ SWOT.pdf?ua=1 [Accessed 15 Apr 2020]

28 Bureau of Immigration, Ministry of Home Affairs, Government of India. Visa restrictions related to COVID-19. Available: https://www. mohfw.gov.in/pdf/VisarestrictionsrelatedtoCOVID19Ministries.pdf [Accessed 29 May 2020].

29 Dasgupta S. India screened only $19 \%$ of inbound passengers for Covid until 23 March, RTI reply reveals. ThePrint, 2020. https:// theprint.in/health/india-screened-only-19-of-inbound-passengersfor-covid-until-23-march-rti-reply-reveals/422140/

30 Weekly Outbreaks. Integrated disease surveillance programme (IDSP) national centre for disease control Directorate General of health services Ministry of health and family welfare government of India, 2020. Available: https://idsp.nic.in/index4.php?lang=1\&level= 0\&linkid=406\&lid=3689 [Accessed 29 May 2020].

31 The Week. 40 people, 3 washrooms, 5 bedrooms: Quarantined woman shares harrowing experience at Dwarka facility. Available: https://www.theweek.in/news/india/2020/03/17/40people-3-washrooms-5-bedrooms-quarantined-woman-sharesharrowing-experience-at-dwarka-facility.html [Accessed $10 \mathrm{Jul}$ 2020].

32 Quartz India [Internet]. Why are patients fleeing India's coronavirus isolation wards? Available: https://qz.com/india/1819659/why-arepatients-fleeing-indias-coronavirus-isolation-wards/ [Accessed 10 Jul 2020].

33 John TJ, Moorthy M. 2009 pandemic influenza in India. Indian Pediatr 2010;47:25-31. 